\title{
Prophylactic effects of Bacille Calmette-Guérin intravesical instillation therapy: Time period-related comparison between Japan and Western countries
}

\author{
Takehiko Okamura • Ryosuke Ando • Hidetoshi Akita • \\ Noriyasu Kawai $\cdot$ Keiichi Tozawa $\cdot$ Kenjiro Kohri • \\ Hideo Arano
}

Published online: 28 December 2013

(C) The Author(s) 2013. This article is published with open access at Springerlink.com

\begin{abstract}
Guidelines change every few years regarding the prophylactic use of Bacille Calmette-Guérin (BCG) against non-muscle invasive bladder cancer. We performed a retrospective comparison to clarify the differences in BCG efficacy, based on time period, between Japan and Western countries. Published literature on 18 Japanese and 28 Western patient studies were compared to evaluate differences in BCG efficacy. Additionally, Internet searches were performed to obtain comparative Japanese and Western data. BCG efficacy in Japanese literature tended to show decreasing nonrecurrence rates by time period. Non-recurrence rates in Western countries increased each year. This discrepancy may stem from a number of factors, including changes in accepted BCG indications, the introduction of restaging transurethral resection (re-TUR), the concept of BCG maintenance, and the evolution of histopathological diagnostic criteria.
\end{abstract}

This article is part of the Topical Collection on Urothelial Cancer

T. Okamura $(\bowtie) \cdot$ R. Ando $\cdot$ H. Akita

Department of Urology, J.A. Aichi Anjo Kosei Hospital, 28

Higashihirokute, Anjo-cho, Anjo 446-8602, Japan

e-mail: hiko2546@sf.commufa.jp

R. Ando $\cdot$ N. Kawai $\cdot$ K. Tozawa $\cdot$ K. Kohri

Department of Nephro-Urology, Nagoya City University Graduate

School of Medical Sciences, Nagoya, Japan

H. Arano

Product Information Department, Japan BCG Laboratory, Tokyo, Japan
Keyword Bacille Calmette-Guérin (BCG) · Intravesical instillation · Non-muscle invasive bladder cancer (NMIBC) . Prophylactic use $\cdot$ Time period-related comparison

\section{Introduction}

For the past two decades, intravesical Bacille Calmette-Guérin (BCG) instillation therapy has been considered the worldwide gold standard for the treatment of non-muscle invasive bladder cancer (NMIBC) [1-3]. Initially, there were no generally accepted guidelines or risk classifications. After trial and error, the first guidelines for BCG indication were published in 1999 by the American Urological Association (AUA) [1]. Subsequently, two major sets of guidelines were published by the European Association of Urology (EAU) [2] and the National Comprehensive Cancer Network (NCCN). These guidelines have been revised annually (http://www.nccn.org/professionals/physician_gls/PDF/ bladder.pdf, http://www.uroweb.org/gls/pdf/05_TaT1_Bladder_ Cancer_LR\%20March\%2013th\%202012.pdf, http://www. auanet.org/content/clinical-practice-guidelines/clinicalguidelines.cfm?sub=bc). Additionally, several guidelines have been developed worldwide. In particular, guidelines for the prophylactic use of BCG against NMIBC have been revised due to modifications in the pathological diagnostic classifications, the introduction and consensus regarding restaging transurethral resection (re-TUR) procedures $[3,4$, $5 \cdot \bullet]$, and other technical or mechanical improvements.

However, there have been no publications concerning the variations in outcome due to changes in the guidelines for $\mathrm{BCG}$ application. Therefore, we conducted a retrospective comparison to clarify differences in BCG efficacy, according to time period, between patients in Japan and Western countries. 


\section{Methods}

Data Selection and Collection

\section{Japanese Literature Records}

A total of 18 papers (22 treatment arms) were chosen according to the criteria described below [6-23]. The literature searches were conducted to include reports published between January 1985 and July 2011. All literature was identified via PubMed database searches, which were limited to human subjects and contained the MeSH term "bladder neoplasms" with additional search terms "BCG" or "bacillus Calmette-Guérin" and "Japan." Additional searches were conducted on the Japanese electronic database JAPIC (Japan Pharmaceutical Information Center). All identified studies were conducted within Japan. The beginning of the studies was clearly described, and the study registration periods occurred within five years. The enrolled cases were limited to those of intermediate to high risk, and the studies did not focus on particular patient categories such as those with carcinoma in situ (CIS) or T1G3 disease. Combinations with other agents that might be influenced by the effects of BCG were excluded, and other anticancer agents were not used.

\section{Western Literature Records}

The literature searches included reports published between January 1985 and May 2012. The searches were limited to reports of human subjects that were published in the English language and included the MeSH term "bladder neoplasms" with additional search terms "BCG" or "bacillus Calmette-Guérin." The initial database search returned a collection of 1,833 reports, which were subsequently narrowed to 228 reports. From these reports, 28 reports (38 treatment arms) were chosen [24-50, 51••], according to the same conditions that were used to select Japanese patient literatures, which are described below. All studies were performed outside of Japan. The beginning of the studies was clearly described, and the registration periods occurred within 5 years. The enrolled cases were limited to those of intermediate to high risk, and the studies did not focus on particular patient categories such as those with CIS or T1G3 disease. Combinations with other agents that might be influenced by the effects of BCG were excluded, and other anticancer agents were not used.

A non-recurrence rate graph based on the above-described data was plotted for each time period at the beginning of the study. In studies that contained two or more BCG treatment arms, every arm was plotted.

\section{Statistical Analyses}

Simple linear regression analysis was used to determine the correlation coefficient between the period of BCG treatment and clinical variables. All statistical analyses were performed using Microsoft Office Excel 2007.

\section{Results}

Most of the Japanese literature reports were published before 2000 [6-17]. Recent reports focused mainly on particular cases such as T1G3 cases or on specific institutional outcomes. BCG studies greater than 10 years in length were reported with increasing frequency after 2000; these reports were unsuitable for our study. Surprisingly, in the 1980s and early 1990s, patients with Ta, G1, or G2 cases were often overlooked [6-14].

This trend changed after a survey by the Japanese Urological Association in 1999-2001 [52]. The patient backgrounds that were considered widened dramatically, and BCG was used to treat many T1 and/or G3 cases. During the survey period, BCG was normally used for high-risk cases.

Figure 1 shows the initial treatment year of the BCG intravesical therapy studies and the 3-year non-recurrence rates. Although the 3-year non-recurrence rate appeared to have decreased gradually in recent years, there was no statistical correlation between the starting year and the 3-year non-recurrence rate.

The correlation between treatment time period and patient age was examined. A trend toward increased patient age was seen in recent years, but no statistical correlation was observed (Fig. 2).

A summary comparison of literature data between the late1990s and earlier periods demonstrates that BCG is widely used in high-risk patients such as T1G3 cases. Furthermore, it is possible that patient age has an effect on therapeutic outcome.

On the other hand, our analyses of the data from Western countries showed a trend toward increased non-recurrence rates (Fig. 3).

With regard to patient background, the percentage of highrisk patients has increased both in Japan and in Western countries (Europe and the United States).

The reported median age of patients in Japanese literature increased by approximately 2 years over a period of greater than 20 years; however, the median age of patients in Western countries was almost unchanged over the time periods studied (Fig. 4).

\section{Discussion}

The results of our study indicated a trend toward decreasing non-recurrence rates in Japanese patients after the year 2000, which may be related to differences in study background characteristics such as greater average numbers of tumors per case or increased numbers of low-dose cases. On the other hand, the prophylactic effects of BCG appeared to increase annually in Western countries. We believe that this is the first 
Fig. 1 Analysis of the correlation between the year of BCG treatment initiation and the 3-year non-recurrent survival rate according to the 18 Japanese patient literature references

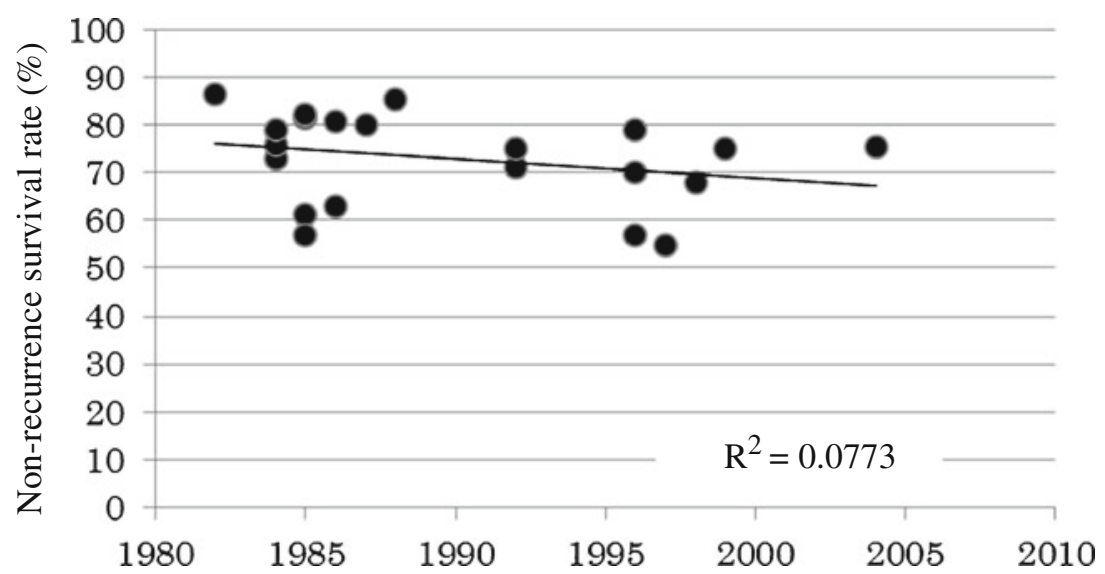

literature review of BCG intravesical instillation therapy stratified by age.

Clearly, there are a number of factors that may account for the trend in the Japanese cases. In the 1980s, BCG was introduced as a promising treatment option for recurrent NMIBC (initially referred to as superficial bladder cancer), which led to the global use of BCG. However, many severe adverse effects were reported, including anaphylactic shock, arthritis, Reiter's syndrome, general tuberculosis infection, and contracted bladder. In response to this, applied doses were reduced [49, 53]. However, most dose-dependent comparisons did not show dose-related variations in efficacy $[54,55]$. Additionally, the BCG indication criteria were changed so that more stringent patient selection guidelines were provided annually in the United States and other countries (AUA, EAU, and NCCN guidelines) (http://www. nccn.org/professionals/physician_gls/PDF/bladder.pdf, http:// www.uroweb.org/gls/pdf/05_TaT1_Bladder_Cancer_LR\%
20March\%2013th\%202012.pdf, http://www.auanet.org/ content/clinical-practice-guidelines/clinical-guidelines.cfm? $\mathrm{sub}=\mathrm{bc}$ ). The applied criteria were also changed in Japan (bladder cancer practice guideline: Japanese Urological Association, 2009).

The Spanish Urological Club for Oncological Treatment reported on a scoring system for factors that affected prognosis in patients who had received intravesical BCG therapy [56]. Age and gender were newly discovered prognostic factors in this study, in contrast to those reported by the European Organisation for Research and Treatment of Cancer, which accounted for almost no BCG cases. However, Tclassification and tumor size were not found to be prognostic factors. These factors may have influenced BCG therapy outcomes in Western countries to some extent.

Although changes in histopathological bladder cancer grading and staging criteria could have an impact, the distinction between high-malignant potential and noninvasive low-malignant potential tumors has received
Fig. 2 Median age distribution according to the 18 Japanese patient references

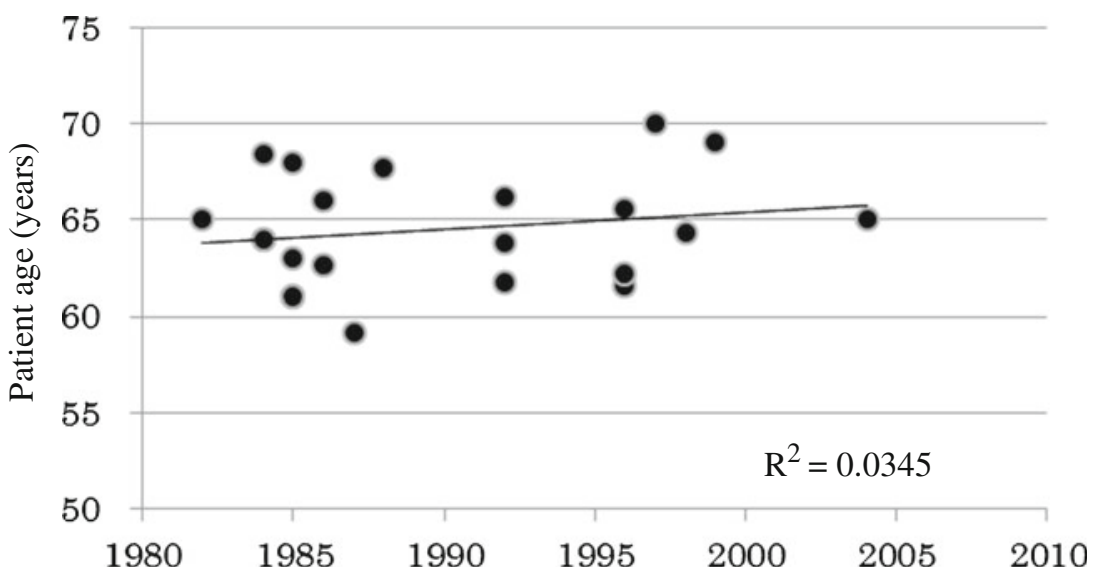


Fig. 3 Analysis of the correlation between the year of BCG treatment initiation and the 3-year non-recurrence survival rate according to the 28 literature references of patients in Western countries

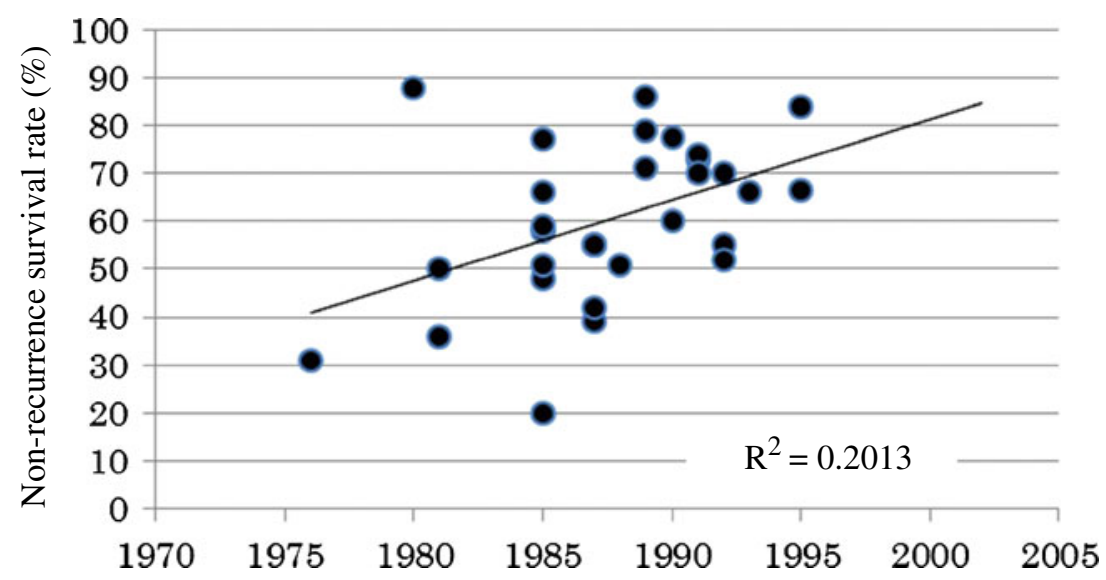

more emphasis. Consequently, the name "superficial bladder cancer" was changed to NMIBC, and in Japan, pathological classifications were modified in the $1990 \mathrm{~s}$ from T1a and T1b to T1 only.

Patient age is another potential factor in Japanese cases. In fact, a trend toward increased patient age at BCG application was observed in the 18 Japanese papers reviewed, as shown in Fig. 2. Several reports, including our own, have described lower efficacy rates for BCG therapy in elderly patients [57-59, 60••]. In Japanese literature, the median patient age increased by approximately 2 years over a 20 -year period. Almost no change in patient age was observed in the Western countries (Fig. 4). The relationship between patient age and BCG efficacy is still not clearly understood.

Number of intravesical BCG instillations is another possible factor. Maintenance therapy has been established in Europe and the United States, and intravesical instillation time is therefore greater than in Japanese cases.

Initially, large numbers of BCG administrations were reported in the Japanese cases, but more recently, the number of administrations was reduced to 6 or 8 . BCG for intravesical, with a treatment schedule of 8 administrations, was first approved in Japan in 1996. Maintenance administrations were approved in 2010 .

We found no direct correlation between patient background and therapeutic strategy transitions. Trial-and-error variability, periods in which targets and methods were more firmly established, and periods of increased maintenance therapy were found to exist in all time periods

\section{Conclusions}

The results of this study revealed an annual trend toward decreasing non-recurrence rates in Japanese studies. However, these results conflicted with those from studies in Western countries. This discrepancy may stem from a number of factors, including changes in accepted BCG indications, the introduction of re-TUR, the concept of BCG maintenance, and the evolution of histopathological diagnostic criteria.
Fig. 4 Median age distribution according to the 28 references of patients in Western countries

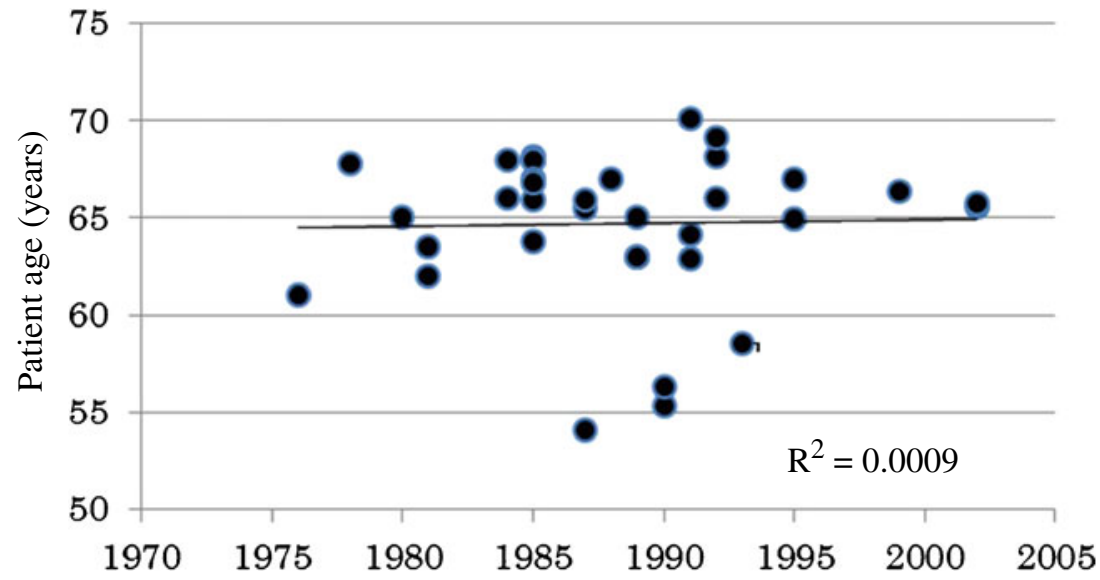




\section{Compliance with Ethics Guidelines}

Conflict of Interest Dr. Takehiko Okamura, Dr. Ryosuke Ando, Dr. Hidetoshi Akita, Dr. Noriyasu Kawai, Dr. Keiichi Tozawa, Dr. Kenjiro Kohri, and Dr. Hideo Arano reported no potential conflicts of interest relevant to this article.

Human and Animal Rights and Informed Consent This article does not contain any studies with human or animal subjects performed by any of the authors.

Open Access This article is distributed under the terms of the Creative Commons Attribution License which permits any use, distribution, and reproduction in any medium, provided the original author(s) and the source are credited.

\section{References}

Papers of particular interest, published recently, have been highlighted as:

- Of importance

.• Of major importance

1. Smith Jr JA, Labasky RF, Cockett AT, Fracchia JA, Montie JE, Rowland RG. Bladder cancer clinical guidelines panel summary report on the management of nonmuscle invasive bladder cancer (stages Ta, T1 and TIS). The American Urological Association. J Urol. 1999;162:1697-701.

2. Oosterlinck W, Lobel B, Jackse G, Malmström PU, Stöckle M, Strenberg C; European Association of Urology. EAU Recommendations 2001. "Guidelines on bladder cancer", 2001.

3. Schwaibold HE, Sivalingam S, May F, Hartung R. The value of a second transurethral resection for T1 bladder cancer. BJU Int. 2006;97:1199-201.

4. Sivalingam S, Probert JL, Schwaibold H. The role of repeat transurethral resection in the management of high-risk superficial transitional cell bladder cancer. BJU Int. 2005;96:759-62.

5. •- Brausi M, Witjes JA, Lamm D, Persad R, Palou J, Colombel M, et al. A review of current guidelines and best practice recommendations for the management of nonmuscle invasive bladder cancer by the International Bladder Cancer Group. J Urol. 2012;186:215867. This paper reports a review of most major current guidelines and emphasized the importance of re-TUR for the management of NMIBC. .

6. Tachibana M, Jitsukawa S, Iigaya T, Shibayama T, Baba S, Deguchi $\mathrm{N}$, et al. Comparative study on prophylactic intravesical instillation of bacillus Calmette-Guerin (BCG) and adriamycin for superficial bladder cancers. Jpn J Urol. 1989;80:1459-65.

7. Yamamoto $T$, Hagiwara $M$, Nakazono $M$, Yamamoto $H$. Intravesical bacillus Calmette-Guerin (BCG) in the treatment of superficial bladder cancer. Prospective randomized study for prophylactic effect. Jpn J Urol. 1990;81:997-1001.

8. Yabusaki N, Komatsu H, Tago K, Yamada Y, Ueno A. Intravesical instillation of bacillus Calmette-Guerin for superficial bladder carcinoma: study on significance of additional maintenance instillations of bacillus Calmette-Guerin. Jpn J Urol. 1991;82:290-6.

9. Ozono S, Tabata S, Kaneko Y, Maruyama Y, Babaya K, Yamada K, et al. Outcomes of intravesical instillation of bacillus CalmetteGuerin (BCG) therapy for superficial bladder cancer. Ann Soc BCG BRM Imm. 1992;16:79-83.
10. Ao T, Uchida T, Yokoyama E, Kawakami T, Adachi K, Mashimo S, et al. Prophylactic combination therapy after TUR of superficial bladder cancer. Acta Urol Jpn. 1993;39:987-91.

11. Kano M, Kanemura M, Yokoyama M. Risk factor of tumor recurrence following intravesical instillation of bacillus Calmette-Guerin (BCG) therapy for superficial bladder cancer. Ann Soc BCG BRM Imm. 1993;17:39-44.

12. Tachibana M, Nakamura S, Jitsukawa S, Deguchi N, Baba S, Hata $\mathrm{M}$, et al. Long-term results and risk factors of tumor recurrence in patients with superficial bladder cancer who were treated by intravesical bacillus Calmette-Guerin (BCG) instillation. Jpn J Urol. 1993;84:656-61.

13. Irie A, Lee KE, Kadowaki K, Sawamura M. Long-term results and complications of intravesical instillation of bacillus CalmetteGuerin for prophylaxis of bladder cancer recurrence. Acta Urol Jpn. 1994;40:873-7.

14. Tanaka T, Shinoda M, Maruyama T, Sasaki H, Naga H, Kuwahara $\mathrm{Y}$, et al. The 25 cases of tumor recurrence after intravesical bacillus Calmette-Guerin therapy for superficial bladder cancer. Ann Soc BCG BRM Imm. 1994;18:95-100.

15. Takashi M, Wakai K, Ohno Y, Murase T, Miyake K. Evaluation of a low-dose intravesical bacillus Calmette-Guérin (Tokyo strain) therapy for superficial bladder cancer. Int Urol and Nephrol. 1995;27:723-33.

16. Ao T, Uchida T, Muramoto M, Ito K, Masui N, Kawakami T, et al. Postoperative intravesical pirarubicin plus bacillus Calmette-Guérin with or without interleukin-2 instillation therapy for superficial bladder cancer. Nishinihon J Urol. 1996;5:538-41.

17. Ozono S, Takashima K, Yoshida K, Hirao Y, Samma S, Okajima E. Intravesical bacillus Calmette-Guerin (BCG) therapy for prophylaxis of the superficial bladder cancer - Outcomes of randomized study-. Ann Soc BCG BRM Imm. 1997;21:87-91.

18. Tozawa K, Okamura T, Yamada Y, Hayashi Y, Sasaki S, Kohri K. Intravesical combined chemoimmunotherapy with epirubicin and bacillus Calmette-Guérin is not indicated for superficial bladder cancer. Urol Int. 2001;67:289-92.

19. Irie A, Uchida T, Yamashita H, Matsumoto K, Satoh T, Koh H, et al. Sufficient prophylactic efficacy with minor adverse effects by intravesical instillation of low-dose bacillus Calmette-Guérin for superficial bladder cancer recurrence. Int J Urol. 2003;10:183-9.

20. Hinotsu S, Akaza H, Isaka S, Kanetake H, Kubota Y, Kuroda M, et al. BCG Tokyo 172 Strain Study Group. Sustained prophylactic effect of intravesical bacille Calmette-Guérin for superficial bladder cancer: a smoothed hazard analysis in a randomized prospective study. Urology. 2006;67:545-9.

21. Kikuchi E, Fujimoto H, Mizutani Y, Okajima E, Koga H, Hinotsu $\mathrm{S}$, et al. Cancer Registration Committee of the Japanese Urological Association. Clinical outcome of tumor recurrence for Ta, T1 nonmuscle invasive bladder cancer from the data on registered bladder cancer patients in Japan: 1999-2001 report from the Japanese Urological Association. Int J Urol. 2009;16:279-86.

22. Segawa N, Inamoto T, Nomi H, Ibuki N, Azuma H, Katsuoka Y. Effect of prophylactic intravesical instillation of BCG for superficial bladder cancer. Acta Urol Jpn. 2009;55:175-80.

23. Hinotsu S, Akaza H, Naito S, Ozono S, Sumiyoshi Y, Noguchi S, et al. Maintenance therapy with bacillus Calmette-Guérin Connaught strain clearly prolongs recurrence-free survival following transurethral resection of bladder tumour for nonmuscleinvasive bladder cancer. BJU Int. 2011;108:187-95.

24. Lamm DL. Bacillus Calmette-Guerin immunotherapy for bladder cancer. J Urol. 1985;134:40-7.

25. Herr HW, Pinsky CM, Whitmore Jr WF, Sogani PG, Oettgen HF, Melamed MR. Experience with intravesical bacillus CalmetteGuèrin therapy of superficial bladder tumors. Urology. 1985;25: 119-23.

26. Badalament RA, Herr HW, Wong GY, Gnecco C, Pinsky $\mathrm{CM}$, Whitmore Jr WF, et al. A prospective randomized trial 
of maintenance versus nonmaintenance intravesical bacillus Calmette-Guérin therapy of superficial bladder cancer. J Clin Oncol. 1987;5:441-9.

27. Martínez-Piñeiro JA, Jiménez León J, Martínez-Piñeiro Jr L, Fiter L, Mosteiro JA, Navarro J, et al. Bacillus Calmette-Guerin versus doxorubicin versus thiotepa: a randomized prospective study in 202 patients with superficial bladder cancer. J Urol. 1990;143:502-6.

28. Lamm DL, DeHaven JI, Shriver J, Crispen R, Grau D, Sarosdy MF. A randomized prospective comparison of oral versus intravesical and percutaneous bacillus Calmette-Guerin for superficial bladder cancer. J Urol. 1990;144:65-7.

29. Jauhiainen KE, Alfthan OS. Instillation therapy in superficial urinary bladder cancer. Finnbladder Group. Scand J Urol Nephrol Suppl. 1991;138:179-85.

30. D'Ancona CA, Netto Júnior NR, Claro JA, Ikari O. Oral or intravesical bacillus Calmette-Guerin immunoprophylaxis in bladder carcinoma. J Urol. 1991;145:498-501.

31. Witjes JA, Fransen MP, van der Meijden AP, Doesburg WH, Debruyne FM. Use of maintenance intravesical bacillus CalmetteGuérin (BCG), with or without intradermal BCG, in patients with recurrent superficial bladder cancer. Long-term follow-up of a randomized phase 2 study. Urol Int. 1993;51:67-72.

32. Lamm DL, Riggs DR, Shriver JS, van Gilder PF, Rach JF, DeHaven JI. Megadose vitamins in bladder cancer: a double-blind clinical trial. J Urol. 1994;151:21-6.

33. Kamat MR, Kulkarni JN, Tongaonkar HB, Dalal AV. Intravesical bacillus Calmette-Guerin for superficial bladder cancer: experience with Danish 1331 strain. J Urol. 1994;152:1424-8.

34. Vegt PD, Witjes JA, Witjes WP, Doesburg WH, Debruyne FM, van der Meijden AP. A randomized study of intravesical mitomycin C, bacillus Calmette-Guerin Tice and bacillus Calmette-Guerin RIVM treatment in pTa-pT1 papillary carcinoma and carcinoma in situ of the bladder. J Urol. 1995;153:929-33.

35. Lamm DL, Blumenstein BA, David Crawford E, Crissman JD, Lowe BA, Smith Jr JA, et al. Randomized intergroup comparison of bacillus calmette-guerin immunotherapy and mitomycin $\mathrm{C}$ chemotherapy prophylaxis in superficial transitional cell carcinoma of the bladder a southwest oncology group study. Urol Oncol. 1995;1:119-26.

36. Lüftenegger W, Ackermann DK, Futterlieb A, Kraft R, Minder CE, Nadelhaft $P$, et al. Intravesical versus intravesical plus intradermal bacillus Calmette-Guerin: a prospective randomized study in patients with recurrent superficial bladder tumors. J Urol. 1996;155: 483-7.

37. Krege S, Giani G, Meyer R, Otto T, Rübben H. A randomized multicenter trial of adjuvant therapy in superficial bladder cancer: transurethral resection only versus transurethral resection plus mitomycin $\mathrm{C}$ versus transurethral resection plus bacillus CalmetteGuerin. Participating Clinics. J Urol. 1996;156:962-6.

38. Gruenwald IE, Stein A, Rashcovitsky R, Shifroni G, Lurie A. A 12 versus 6-week course of bacillus Calmette-Guerin prophylaxis for the treatment of high risk superficial bladder cancer. J Urol. 1997;157:487-91.

39. Yalçinkaya F, Kamiș L, Ozteke O, Günlüsoy B, Yigitbași O, Unal $\mathrm{S}$. Prospective randomized comparison of intravesical BCG therapy with standard dose versus low doses in superficial bladder cancer. Int Urol Nephrol. 1998;30:41-4.

40. Malmstrom PU, Wijkstrom H, Lundholm C, Wester K, Busch C, Norlén BJ. 5-Year followup of a randomized prospective study comparing mitomycin $\mathrm{C}$ and bacillus Calmette-Guerin in patients with superficial bladder carcinoma. Swedish-Norwegian Bladder Cancer Study Group. J Urol. 1999;161:1124-7.

41. Ali-El-Dein B, Nabeeh A, Ismail EH, Ghoneim MA. Sequential bacillus Calmette-Guerin and epirubicin versus bacillus CalmetteGuerin alone for superficial bladder tumors: a randomized prospective study. J Urol. 1999;162:339-42.
42. Lamm DL, Blumenstein BA, Crissman JD, Montie JE, Gottesman JE, Lowe BA, et al. Maintenance bacillus Calmette-Guérin immunotherapy for recurrent $\mathrm{Ta}, \mathrm{T} 1$ and carcinoma in situ transitional cell carcinoma of the bladder cancer: a randomized Southwest Oncology Group Study. J Urol. 2000;163:1124-9.

43. Palou J, Laguna P, Millán-Rodríguez F, Hall RR, Salvador-Bayarri J, Vicente-Rodríguez J. Control group and maintenance treatment with bacillus Calmette-Guerin for carcinoma in situ and/or high grade bladder tumors. J Urol. 2001;165:1488-91.

44. Martínez-Piñeiro JA, Flores N, Isorna S, Solsona E, Sebastián JL, Pertusa C, et al. for CUETO (Club Urológico Español de Tratamiento Oncológico). Long-term follow-up of a randomized prospective trial comparing a standard $81 \mathrm{mg}$ dose of intravesical bacille Calmette-Guérin with a reduced dose of $27 \mathrm{mg}$ in superficial bladder cancer. BJU Int. 2002;89:671-80.

45. Librenjak D, Situm M, Eterovic D, Dogas Z, Gotovac J. Immunoprophylactic intravesical application of bacillus CalmetteGuerin after transurethral resection of superficial bladder cancer. Croat Med J. 2003;44:187-92.

46. Cheng CW, Chan SF, Chan LW, Chan CK, Ng CF, Cheung HY, et al. Twelve-year follow up of a randomized prospective trial comparing bacillus Calmette-Guerin and epirubicin as adjuvant therapy in superficial bladder cancer. Int J Urol. 2005;12:449-55.

47. Colombel M, Saint F, Chopin D, Malavaud B, Nicolas L, Rischmann P. The effect of ofloxacin on bacillus calmette-guerin induced toxicity in patients with superficial bladder cancer: results of a randomized, prospective, double-blind, placebo controlled, multicenter study. J Urol. 2006;176:935-9.

48. Friedrich MG, Pichlmeier U, Schwaibold H, Conrad S, Huland H. Long-term intravesical adjuvant chemotherapy further reduces recurrence rate compared with short-term intravesical chemotherapy and short-term therapy with Bacillus Calmette-Guérin (BCG) in patients with non-muscle-invasive bladder carcinoma. Eur Urol. 2007;52:1123-9.

49. Ojea A, Nogueira JL, Solsona E, Flores N, Gómez JM, Molina JR, et al. CUETO Group (Club Urológico Español De Tratamiento Oncológico). A multicentre, randomised prospective trial comparing three intravesical adjuvant therapies for intermediate-risk superficial bladder cancer: low-dose bacillus Calmette-Guerin $(27 \mathrm{mg})$ versus very low-dose bacillus Calmette-Guerin (13.5 mg) versus mitomycin C. Eur Urol. 2007;52:1398-406.

50. Duchek M, Johansson R, Jahnson S, Mestad O, Hellström P, Hellsten S, et al. Members of the Urothelial Cancer Group of the Nordic Association of Urology. Bacillus Calmette-Guérin is superior to a combination of epirubicin and interferon-alpha $2 b$ in the intravesical treatment of patients with stage T1 urinary bladder cancer. A prospective, randomized, Nordic study. Eur Urol. 2010;57:25-31.

51. •- Sylvester RJ, Brausi MA, Kirkels WJ, Hoeltl W, Calais Da Silva F, Powell PH, et al. Long-term efficacy results of EORTC genitourinary group randomized phase 3 study 30911 comparing intravesical instillations of epirubicin, bacillus Calmette-Guérin, and bacillus Calmette-Guérin plus isoniazid in patients with intermediate- and high-risk stage Ta T1 urothelial carcinoma of the bladder. Eur Urol. 2010;57:766-73. This reference emphasized the superior efficacy of maintenance BCG therapy, comparing anticancer drug even in intermediate risk group.

52. Kikuchi E, Fujimoto H, Mizutani Y, Okajima E, Koga H, Hinotsu S, et al. Mototsugu Oya and Tsuneharu Miki, the Cancer Registration Committee of the Japanese Urological Association Clinical outcome of tumor recurrence for Ta, T1 non-muscle invasive bladder cancer from the data on registered bladder cancer patients in Japan: 1999-2001 report from the Japanese Urological Association. Int J Urol. 2009;16:279-86. 
53. Yoneyama $\mathrm{T}$, Ohyama $\mathrm{C}$, Imai A, Ishimura $\mathrm{H}$, Hagisawa $\mathrm{S}$, Iwabuchi I, et al. Low-dose instillation therapy with bacille Calmette-Guérin Tokyo 172 strain after transurethral resection: historical cohort study. Urology. 2008;71:1161-5.

54. Martínez-Piñeiro JA, Martínez-Piñeiro L, Solsona E, Rodríguez RH, Gómez JM, Martín MG, et al. Club Urológico Español de Tratamiento Oncológico (CUETO). Has a 3-fold decreased dose of Bacillus Calmette-Guérin the same efficacy against recurrences and progression of T1G3 and Tis bladder tumors than the standard dose? Results of a prospective randomized trial. J Urol. 2005;174:1242-7.

55. Sylvester RJ. Bacillus Calmette-Guérin treatment of non-muscle invasive bladder cancer. Int J Urol. 2011;18:113-20.

56. Fernandez-Gomez J, Madero R, Solsona E, Unda M, Martinez-Piñeiro $\mathrm{L}$, Gonzalez $\mathrm{M}$, et al. Predicting nonmuscle invasive bladder cancer recurrence and progression in patients treated with bacillus CalmetteGuerin: the CUETO scoring model. J Urol. 2009;182:2195-203.
57. Joudi FN, Smith BJ, O'Donnell MA, Konety BR. The impact of age on the response of patients with superficial bladder cancer to intravesical immunotherapy. J Urol. 2006;175:1634-40.

58. Kohjimoto Y, Iba A, Shintani Y, Inagaki T, Uekado Y, Hara I. Impact of patient age on outcome following bladder-preserving treatment for non-muscle-invasive bladder cancer. World J Urol. 2010;28:425-30.

59. Okamura T, Akita H, Hashimoto Y, Tozawa K, Hinotsu S, Akaza H, et al. Non Muscle Invasive Bladder Cancer Cases Initially Failing to Respond to Bacillus Calmette-Guérin Intravesical Instillation Therapy. Curr Urol. 2010;4:18-24.

60. - Margel D, Alkhateeb SS, Finelli A, Fleshner N. Diminished efficacy of Bacille Calmette-Guérin among elderly patients with nonmuscle invasive bladder cancer. Urology. 2011;78:848-55. This study demonstrated the accurate diminished efficacy of $B C G$ among elderly patients rather than younger ones. . 